\title{
Epidemiological Trends of Maternal Hypertensive Disorders of Pregnancy at the Global, Regional, and National Levels: A Population-Based Study
}

\section{Wei Wang}

The First Affiliated Hospital of Xi'an Jiaotong University

\section{Xin Xie}

The First Affiliated Hospital of Xi'an Jiaotong University

\section{Ting Yuan}

The First Affiliated Hospital of Xi'an Jiaotong University

\section{Yanyan Wang}

The First Affiliated Hospital of Xi'an Jiaotong University

\section{Fei Zhao}

The First Affiliated Hospital of Xi'an Jiaotong University

\section{Zhangjian Zhou}

The Second Affiliated Hospital of Xi'an Jiaotong University

Hao Zhang ( $\square$ hao.zhang@mail.xjtu.edu.cn )

The First Affiliated Hospital of Xi'an Jiaotong University https://orcid.org/0000-0001-8986-3854

\section{Research article}

Keywords: hypertensive disorders of pregnancy, burden of disease, sociodemographic index, human development index

Posted Date: January 18th, 2021

DOI: https://doi.org/10.21203/rs.3.rs-146936/v1

License: (c) (i) This work is licensed under a Creative Commons Attribution 4.0 International License. Read Full License 


\section{Abstract}

Background. To report the cause-specific prevalence and trends of hypertensive disorders of pregnancy at global, regional and national levels from 1990 to 2019 by age and sociodemographic index.

Methods. For hypertensive disorders of pregnancy, point prevalence, annual incidence, and years lived with disability numbers and age standardized rates per 100,000 population were compared across regional and national levels by age and sociodemographic index using data from the global Burden of Disease 2019 Study. Estimates are reported with uncertainty intervals.

Results. The incidence of hypertensive disorders of pregnancy increased from 16.30 million to 18.08 million globally, with a total increase of $10.92 \%$ from 1990 to 2019 . The age-standardized incidence rate decreased, with an estimated annual percentage change of -0.68 ( $95 \% \mathrm{Cl}-0.49$ to -0.86$)$. The number of deaths due to hypertensive disorders of pregnancy was approximately 27.83 thousand in 2019 . This was a $30.05 \%$ decreased from 1990. Based on the incidence and prevalence, the number of deaths and years lived with disability were highest in the group aged 25-29 years, followed by the groups aged 30-34 and 20-24 years, while the estimated incidence rate was lowest in the group aged 25-29 years and higher in the youngest and oldest groups. Positive associations between incidence and sociodemographic index and human development index were found for all countries and regions in 2019. Age-standardized incidence rates were higher in countries/regions with lower sociodemographic indices and human development indices.

Conclusion. Our study provides a comprehensive overview of the global burden of hypertensive disorders of pregnancy. The death and incidence burdens are decreasing in most countries and all regions except lowsociodemographic and -human development index areas. This is mainly because attention to prenatal examinations and health education has increased. Further investigations should focus on forecasting the global disease burden of specific hypertensive disorders of pregnancy and modifiable risk factors.

\section{Background}

Hypertensive disorders of pregnancy (HDP) is generally classified into four categories: gestational hypertension, preeclampsia/eclampsia, chronic hypertension, and chronic hypertension complicated with preeclampsia/eclampsia. In 2013, the American Congress of Obstetricians and Gynecologists (ACOG) guidelines on hypertensive disorder complicating pregnancy adopted this classification.(1) The 2018 International Society for the Study of Hypertension in Pregnancy (ISSHP) guidelines classify HDP into two categories.(2) The first category is hypertension diagnosed before pregnancy or newly discovered before 20 weeks of pregnancy, including three subtypes: chronic hypertension (primary and secondary), white coat hypertension and concealed hypertension. The second category is hypertension that occurs after 20 weeks of pregnancy, including three subtypes: transient pregnancy hypertension, pregnancy hypertension and preeclampsia (new or progressed from chronic hypertension). The classification includes three special types of HDP: white coat hypertension, concealed hypertension and transient hypertension. The 2020 International Society of Hypertension (ISH) guidelines continue the framework of the four-category HDP classification scheme, where hemolytic anemia, elevated liver function and low platelet count syndrome (HELLP syndrome) are classified in a separate category.(3) Regardless of how HDP is classified, the importance of blood pressure 
monitoring during pregnancy is emphasized. HDP remains one of the leading causes of maternal and fetal morbidity and mortality worldwide.(4)

Recent evidence has indicated that the incidence rate of HDP has increased over the past decades $(7,8)$, suggesting that HDP as a sex-specific cardiovascular disease will become increasingly important in the years to come.(5) Although the importance of HDP in risk assessment and prevention programs has been recognized, the epidemiology of HDP is not well understood. The incidence of HDP ranges from 4-25\% $(5,6)$, and HDP is one of the three leading causes of maternal morbidity and mortality worldwide. In the past half century, the incidence of preeclampsia and maternal mortality have decreased significantly in developed countries. However, in developing countries, the incidence of preeclampsia and maternal mortality are still very high.(7) According to the results of a meta-analysis, the incidence of preeclampsia worldwide is $4.6 \%$ [ $95 \%$ confidence intervals $(\mathrm{Cl}), 2.7-8.2]$, which varies among different regions, such as $1.0 \%$ in the eastern Mediterranean and 5.6\% in Africa.(7) The incidence of preeclampsia also varies among different countries and regions.(8-12) This makes it difficult to estimate the disease burden of HDP.

In recent years, the burden of HDP has been presented in some review papers based on few national studies, but no detailed information from all countries has been provided. The overall aim of this study was to determine the epidemiological characteristics of HDP in a population-based cohort. To provide comprehensive, comparable and up to date information on the HDP burden, this report presents the modeled global-, regionaland national-level prevalence and incidence rates, mortality rates and years lived with disability (YLDs) of HDP as revealed in the Global Burden of Diseases, Injuries, and Risk Factors Study (GBD) 2019; this study presents counts and age-standardized rates from 1990 to 2019 by age, sociodemographic index (SDI), human development index (HDI) and other factors.

\section{Methods}

\section{Data acquisition}

Annual data (inclusive dates: 1990 to 2019) on prevalence, incidence, death, disability-adjusted life years (DALYs), YLDs, years of life lost (YLLs) and the corresponding age-standardized rates (ASRs) as well as risk factors attributable to HDP were searched in the Global Health Data Exchange (GHDx) database (http://ghdx.healthdata.org/). These data were segmented by SDI quintiles and countries/regions. The SDI reflects the degree of social development and correlates with total fertility, per capita income, and average years of education.(13) HDI data for 1990 and 2019 were available for 189 countries and regions in the Human Development Report 2019 and Human Development Index Ranking 2019 (http://hdr.undp.org/en/content/2019-human-development-index-ranking). All countries and regions were sorted into five quintiles based on SDI (http://ghdx.healthdata.org/record/ihme-data/gbd-2019sociodemographic-index-sdi-1950-2019). Risk was defined as exposure, behaviors, or other factors that were causally related to an increased (or decreased) probability of HDP. If the probability decreased, the factor was considered a protective factor.

Estimating the number of pregnant women in a population 
First, the number of live births in the target year was estimated (i). Second, the number of pregnancies that ended in stillbirths or miscarriages was estimated (ii) (estimated at $15 \%$ of live births $=i \times 0.15$ ). Finally, the estimated number of pregnancies expected in a given year was i + ii.(14) Data related to the fertility rate can be found on the website http://ghdx.healthdata.org/record/ihme-data/gbd-2019-fertility-estimates-1950-2019.

Statistical analyses

ASRs were analyzed to compare the HDP incidence and mortality trends among different cohorts. DALYs refer to the years lived with disability and years of life lost.(15) Estimated annual percentage changes (EAPCs) indicate ASR trends during a defined period. The specific EAPC was calculated using a generalized linear model (GLM) considering a Gaussian distribution for the ASR. Under the assumption of linearity on the log scale, which is equivalent to a constant change assumption, the EAPC was calculated. World maps and graphs were generated to display the distribution and change trends of global, regional, and national disease burdens attributable to HDP. All calculations and figures were performed and made using EXCEL 2019 (Microsoft Corporation) and R software (version 4.0.0) with "Rcan", "ggplot2" and other packages, respectively.

\section{Results}

Global level

The incidence of HDP increased from 16.30 million [95\% uncertainty intervals (UI) 13.56 to 19.42 million] to 18.08 million (95\% UI 15.26 to 21.11 million) globally, with a total increase of $10.92 \%$ from 1990 to 2019 . The number of deaths due to HDP was approximately 27.83 thousand ( $95 \%$ UI 24.30 to 27.83 thousand) in 2019. There was a $30.05 \%$ (95\% UI 28.92-32.71\%) decrease from 1990 to 2019 (Table 1). At the global level, the age-standardized incidence rate (ASIR) decreased from 579 (95\% UI 482 to 689) per 100,000 population in 1990 to 463 (95\% UI 392 to 541 ) per 100,000 population in 2019, with an EAPC of -0.68 (95\% Cl -0.49 to -0.86 ); the EAPC of the age-standardized deaths rate (ASDR) was - 2.38 (95\% Cl 1.67 to -6.27 ) (Table 1). 
Table 1

The prevalence of HDP by Global Burden of Disease regions

\begin{tabular}{|c|c|c|c|c|c|c|c|c|}
\hline \multirow[t]{2}{*}{ Characteristics } & \multicolumn{3}{|l|}{1990} & \multicolumn{3}{|l|}{2019} & \multicolumn{2}{|c|}{ 1990-2019 } \\
\hline & $\begin{array}{l}\text { Incidence } \\
\text { No. } \times 10^{5} \\
(95 \% \mathrm{UI})\end{array}$ & $\begin{array}{l}\text { ASIR } \times \\
10^{2} \\
(95 \% \\
\text { UI) }\end{array}$ & $\begin{array}{l}\text { Death } \\
\text { No. } \\
\times 10^{3} \\
(95 \% \\
\text { UI) }\end{array}$ & $\begin{array}{l}\text { Incidence } \\
\text { No. } \times 10^{4} \\
(95 \% \mathrm{UI})\end{array}$ & $\begin{array}{l}\text { ASIR } \times \\
10^{2}(95 \% \\
\text { UI) }\end{array}$ & $\begin{array}{l}\text { Death } \\
\text { No. } \\
\times 10^{3} \\
(95 \% \\
\text { UI) }\end{array}$ & $\begin{array}{l}\text { EAPC } \\
\text { of } \\
\text { ASIR } \\
(95 \% \\
\text { CI) }\end{array}$ & $\begin{array}{l}\text { EAPC } \\
\text { of } \\
\text { ASDR } \\
(95 \% \\
\text { Cl) }\end{array}$ \\
\hline Global & $\begin{array}{l}162.96 \\
(194.2- \\
135.56)\end{array}$ & $\begin{array}{l}5.79 \\
(6.89- \\
4.82)\end{array}$ & $\begin{array}{l}39.79 \\
(43.78- \\
36.11)\end{array}$ & $\begin{array}{l}180.76 \\
(211.08- \\
152.64)\end{array}$ & $\begin{array}{l}4.63 \\
(5.41- \\
3.92)\end{array}$ & $\begin{array}{l}27.83 \\
(31.56- \\
24.3)\end{array}$ & $\begin{array}{l}-0.68 \\
(-0.49 \\
- \\
-0.86)\end{array}$ & $\begin{array}{l}-2.38 \\
(1.67- \\
-6.27)\end{array}$ \\
\hline East Asia & $\begin{array}{l}13.9 \\
(17.7- \\
11.03)\end{array}$ & $\begin{array}{l}1.91 \\
(2.43- \\
1.51)\end{array}$ & $\begin{array}{l}2.44 \\
(2.99- \\
1.96)\end{array}$ & $\begin{array}{l}7.34 \\
(9.07- \\
5.96)\end{array}$ & $\begin{array}{l}0.98 \\
(1.2- \\
0.81)\end{array}$ & $\begin{array}{l}0.19 \\
(0.23- \\
0.14)\end{array}$ & $\begin{array}{l}-1.52 \\
(-1.13 \\
--1.9)\end{array}$ & $\begin{array}{l}-8.17 \\
(4.08- \\
-18.99)\end{array}$ \\
\hline $\begin{array}{l}\text { Southeast } \\
\text { Asia }\end{array}$ & $\begin{array}{l}16.63 \\
(20.5- \\
13.37)\end{array}$ & $\begin{array}{l}6.61 \\
(8.05- \\
5.32)\end{array}$ & $\begin{array}{l}4.62 \\
(5.5- \\
3.96)\end{array}$ & $\begin{array}{l}14.79 \\
(17.78- \\
12.06)\end{array}$ & $\begin{array}{l}4.11 \\
(4.95- \\
3.36)\end{array}$ & $\begin{array}{l}2.51 \\
(3.01- \\
2.07)\end{array}$ & $\begin{array}{l}-1.61 \\
(-1.43 \\
- \\
-1.78)\end{array}$ & $\begin{array}{l}-3.28 \\
(0.38- \\
-6.8)\end{array}$ \\
\hline Oceania & $\begin{array}{l}0.19 \\
(0.23- \\
0.15)\end{array}$ & $\begin{array}{l}5.98 \\
(7.4- \\
4.73)\end{array}$ & $\begin{array}{l}0.06 \\
(0.07- \\
0.04)\end{array}$ & $\begin{array}{l}0.37 \\
(0.46- \\
0.3)\end{array}$ & $\begin{array}{l}5.46 \\
(6.82- \\
4.36)\end{array}$ & $\begin{array}{l}0.11 \\
(0.15- \\
0.08)\end{array}$ & $\begin{array}{l}-0.37 \\
(-0.2- \\
-0.54)\end{array}$ & $\begin{array}{l}-0.23 \\
(2.79- \\
-3.17)\end{array}$ \\
\hline Central Asia & $\begin{array}{l}0.75 \\
(0.93- \\
0.6)\end{array}$ & $\begin{array}{l}2.07 \\
(2.56- \\
1.67)\end{array}$ & $\begin{array}{l}0.16 \\
(0.17- \\
0.14)\end{array}$ & $\begin{array}{l}0.86 \\
(1.08- \\
0.69)\end{array}$ & $\begin{array}{l}1.69 \\
(2.11- \\
1.36)\end{array}$ & $\begin{array}{l}0.09 \\
(0.11- \\
0.08)\end{array}$ & $\begin{array}{l}-0.15 \\
(0.17 \\
- \\
-0.48)\end{array}$ & $\begin{array}{l}-2.68 \\
(5.47- \\
-10.21)\end{array}$ \\
\hline Central Europe & $\begin{array}{l}1.12 \\
(1.44- \\
0.86)\end{array}$ & $\begin{array}{l}1.96 \\
(2.54- \\
1.5)\end{array}$ & $\begin{array}{l}0.04 \\
(0.04- \\
0.03)\end{array}$ & $\begin{array}{l}0.78 \\
(0.94- \\
0.64)\end{array}$ & $\begin{array}{l}1.61 \\
(1.93- \\
1.32)\end{array}$ & $\begin{array}{l}0.01 \\
(0.01- \\
0.01)\end{array}$ & $\begin{array}{l}-0.74 \\
(-0.4- \\
-1.07)\end{array}$ & $\begin{array}{l}-4.62 \\
(21.47 \\
--25.1)\end{array}$ \\
\hline $\begin{array}{l}\text { Eastern } \\
\text { Europe }\end{array}$ & $\begin{array}{l}3.99 \\
(5.22- \\
3.02)\end{array}$ & $\begin{array}{l}3.78 \\
(4.96- \\
2.84)\end{array}$ & $\begin{array}{l}0.15 \\
(0.17- \\
0.14)\end{array}$ & $\begin{array}{l}3.39 \\
(4.28- \\
2.55)\end{array}$ & $\begin{array}{l}3.67 \\
(4.64- \\
2.79)\end{array}$ & $\begin{array}{l}0.03 \\
(0.03- \\
0.02)\end{array}$ & $\begin{array}{l}0.86 \\
(1.1- \\
0.63)\end{array}$ & $\begin{array}{l}-5.87 \\
(11.56 \\
- \\
-20.58)\end{array}$ \\
\hline $\begin{array}{l}\text { High-income } \\
\text { Asia Pacific }\end{array}$ & $\begin{array}{l}1.66 \\
(2.07- \\
1.3)\end{array}$ & $\begin{array}{l}1.92 \\
(2.4- \\
1.5)\end{array}$ & $\begin{array}{l}0.06 \\
(0.07- \\
0.05)\end{array}$ & $\begin{array}{l}1.11 \\
(1.3- \\
0.95)\end{array}$ & $\begin{array}{l}1.44 \\
(1.69- \\
1.24)\end{array}$ & $\begin{array}{l}0.01 \\
(0.01- \\
0.01)\end{array}$ & $\begin{array}{l}-1.71 \\
(-1.39 \\
- \\
-2.03)\end{array}$ & $\begin{array}{l}-7.65 \\
(22.6- \\
-30.44)\end{array}$ \\
\hline Australasia & $\begin{array}{l}0.34(0.4 \\
-0.28)\end{array}$ & $\begin{array}{l}3.08 \\
(3.66- \\
2.56)\end{array}$ & $0(0-0)$ & $\begin{array}{l}0.3(0.39 \\
-0.23)\end{array}$ & $\begin{array}{l}2.17 \\
(2.76- \\
1.67)\end{array}$ & $0(0-0)$ & $\begin{array}{l}-1.26 \\
(-0.99 \\
- \\
-1.52)\end{array}$ & $\begin{array}{l}-2.85 \\
(26.23 \\
- \\
-25.22)\end{array}$ \\
\hline $\begin{array}{l}\text { Western } \\
\text { Europe }\end{array}$ & $\begin{array}{l}3.48 \\
(4.43- \\
2.71)\end{array}$ & $\begin{array}{l}1.79 \\
(2.27- \\
1.4)\end{array}$ & $\begin{array}{l}0.08 \\
(0.09- \\
0.08)\end{array}$ & $\begin{array}{l}3.6 \\
(4.59- \\
2.77)\end{array}$ & $\begin{array}{l}1.94 \\
(2.48- \\
1.51)\end{array}$ & $\begin{array}{l}0.02 \\
(0.03- \\
0.02)\end{array}$ & $\begin{array}{l}0.19 \\
(0.51 \\
- \\
-0.12)\end{array}$ & $\begin{array}{l}-3.91 \\
(26.23 \\
- \\
-26.85)\end{array}$ \\
\hline
\end{tabular}




\begin{tabular}{|c|c|c|c|c|c|c|c|c|}
\hline Characteristics & 1990 & & & 2019 & & & 1990- & 019 \\
\hline $\begin{array}{l}\text { Southern Latin } \\
\text { America }\end{array}$ & $\begin{array}{l}0.95 \\
(1.2- \\
0.74)\end{array}$ & $\begin{array}{l}3.78 \\
(4.73- \\
2.93)\end{array}$ & $\begin{array}{l}0.1 \\
(0.11- \\
0.09)\end{array}$ & $\begin{array}{l}1.11 \\
(1.38- \\
0.86)\end{array}$ & $\begin{array}{l}3.23 \\
(4.03- \\
2.51)\end{array}$ & $\begin{array}{l}0.06 \\
(0.06- \\
0.05)\end{array}$ & $\begin{array}{l}-0.52 \\
(-0.3- \\
-0.74)\end{array}$ & $\begin{array}{l}-2.89 \\
(5.45- \\
-10.58)\end{array}$ \\
\hline $\begin{array}{l}\text { High-income } \\
\text { North America }\end{array}$ & $\begin{array}{l}5.41 \\
(6.95- \\
4.17)\end{array}$ & $\begin{array}{l}3.67 \\
(4.72- \\
2.85)\end{array}$ & $\begin{array}{l}0.07 \\
(0.08- \\
0.07)\end{array}$ & $\begin{array}{l}5.36 \\
(6.09- \\
4.67)\end{array}$ & $\begin{array}{l}3.24 \\
(3.68- \\
2.83)\end{array}$ & $\begin{array}{l}0.09 \\
(0.11- \\
0.08)\end{array}$ & $\begin{array}{l}-0.4 \\
(-0.18 \\
- \\
-0.62)\end{array}$ & $\begin{array}{l}1.11 \\
(19.5- \\
-14.45)\end{array}$ \\
\hline Caribbean & $\begin{array}{l}0.94 \\
(1.16- \\
0.76)\end{array}$ & $\begin{array}{l}4.73 \\
(5.76- \\
3.82)\end{array}$ & $\begin{array}{l}0.21 \\
(0.25- \\
0.18)\end{array}$ & $\begin{array}{l}0.86 \\
(1.04- \\
0.69)\end{array}$ & $\begin{array}{l}3.55 \\
(4.29- \\
2.88)\end{array}$ & $\begin{array}{l}0.34 \\
(0.45- \\
0.26)\end{array}$ & $\begin{array}{l}-0.91 \\
(-0.71 \\
- \\
-1.12)\end{array}$ & $\begin{array}{l}1.63 \\
(5.39- \\
-2)\end{array}$ \\
\hline $\begin{array}{l}\text { Andean Latin } \\
\text { America }\end{array}$ & $\begin{array}{l}0.57 \\
(0.65- \\
0.51)\end{array}$ & $\begin{array}{l}2.91 \\
(3.28- \\
2.62)\end{array}$ & $\begin{array}{l}0.69 \\
(0.79- \\
0.6)\end{array}$ & $\begin{array}{l}0.98 \\
(1.05- \\
0.91)\end{array}$ & $\begin{array}{l}2.91 \\
(3.13- \\
2.73)\end{array}$ & $\begin{array}{l}0.36 \\
(0.47- \\
0.26)\end{array}$ & $\begin{array}{l}0.06 \\
(0.29 \\
- \\
-0.17)\end{array}$ & $\begin{array}{l}-4.49 \\
(-1.72- \\
-7.17)\end{array}$ \\
\hline $\begin{array}{l}\text { Central Latin } \\
\text { America }\end{array}$ & $\begin{array}{l}5.61 \\
(6.69- \\
4.7)\end{array}$ & $\begin{array}{l}6.24 \\
(7.39- \\
5.23)\end{array}$ & $\begin{array}{l}1.03 \\
(1.1- \\
0.97)\end{array}$ & $\begin{array}{l}4.87 \\
(5.54- \\
4.27)\end{array}$ & $\begin{array}{l}3.6 \\
(4.08- \\
3.15)\end{array}$ & $\begin{array}{l}0.65 \\
(0.8- \\
0.52)\end{array}$ & $\begin{array}{l}-1.46 \\
(-1.25 \\
- \\
-1.66)\end{array}$ & $\begin{array}{l}-3.33 \\
(1.35- \\
-7.8)\end{array}$ \\
\hline $\begin{array}{l}\text { Tropical Latin } \\
\text { America }\end{array}$ & $\begin{array}{l}3.59 \\
(4.45- \\
2.87)\end{array}$ & $\begin{array}{l}4.17 \\
(5.13- \\
3.36)\end{array}$ & $\begin{array}{l}0.96 \\
(1.04- \\
0.88)\end{array}$ & $\begin{array}{l}3.29 \\
(3.85- \\
2.82)\end{array}$ & $\begin{array}{l}2.77 \\
(3.24- \\
2.38)\end{array}$ & $\begin{array}{l}0.42 \\
(0.46- \\
0.37)\end{array}$ & $\begin{array}{l}-1.49 \\
(-1.26 \\
- \\
-1.72)\end{array}$ & $\begin{array}{l}-3.67 \\
(1.89- \\
-8.93)\end{array}$ \\
\hline $\begin{array}{l}\text { North Africa } \\
\text { and Middle } \\
\text { East }\end{array}$ & $\begin{array}{l}10.9 \\
(13.46- \\
8.75)\end{array}$ & $\begin{array}{l}6.65 \\
(8.18- \\
5.37)\end{array}$ & $\begin{array}{l}2.83 \\
(3.21- \\
2.49)\end{array}$ & $\begin{array}{l}11.72 \\
(14.33- \\
9.46)\end{array}$ & $\begin{array}{l}3.59 \\
(4.37- \\
2.91)\end{array}$ & $\begin{array}{l}1.75 \\
(2.28- \\
1.33)\end{array}$ & $\begin{array}{l}-1.71 \\
(-1.52 \\
--1.9)\end{array}$ & $\begin{array}{l}-4.18 \\
(-0.18- \\
-8.01)\end{array}$ \\
\hline South Asia & $\begin{array}{l}43.52 \\
(52.47- \\
35.78)\end{array}$ & $\begin{array}{l}8.09 \\
(9.69- \\
6.69)\end{array}$ & $\begin{array}{l}18.74 \\
(21.28- \\
16.21)\end{array}$ & $\begin{array}{l}38.38 \\
(46.18- \\
31.61)\end{array}$ & $\begin{array}{l}3.89 \\
(4.67- \\
3.21)\end{array}$ & $\begin{array}{l}10.34 \\
(12.45- \\
8.34)\end{array}$ & $\begin{array}{l}-2.7 \\
(-2.54 \\
- \\
-2.87)\end{array}$ & $\begin{array}{l}-4.14 \\
(-1.28- \\
-6.91)\end{array}$ \\
\hline $\begin{array}{l}\text { Central Sub- } \\
\text { Saharan } \\
\text { Africa }\end{array}$ & $\begin{array}{l}5.71 \\
(6.75- \\
4.68)\end{array}$ & $\begin{array}{l}22.42 \\
(26.13- \\
18.56)\end{array}$ & $\begin{array}{l}1.03 \\
(1.3- \\
0.79)\end{array}$ & $\begin{array}{l}9.71 \\
(11.54- \\
7.99)\end{array}$ & $\begin{array}{l}15.18 \\
(17.9- \\
12.59)\end{array}$ & $\begin{array}{l}1.69 \\
(2.11- \\
1.26)\end{array}$ & $\begin{array}{l}-1.19 \\
(-1.09 \\
- \\
-1.28)\end{array}$ & $\begin{array}{l}-0.92 \\
(1.2- \\
-3.01)\end{array}$ \\
\hline $\begin{array}{l}\text { Eastern Sub- } \\
\text { Saharan } \\
\text { Africa }\end{array}$ & $\begin{array}{l}19.81 \\
(23.16- \\
16.68)\end{array}$ & $\begin{array}{l}22.46 \\
(25.89- \\
19.11)\end{array}$ & $\begin{array}{l}3.32 \\
(3.94- \\
2.76)\end{array}$ & $\begin{array}{l}31.19 \\
(36.29- \\
26.39)\end{array}$ & $\begin{array}{l}14.96 \\
(17.23- \\
12.71)\end{array}$ & $\begin{array}{l}4.65 \\
(5.7- \\
3.72)\end{array}$ & $\begin{array}{l}-1.32 \\
(-1.23 \\
- \\
-1.41)\end{array}$ & $\begin{array}{l}-1.47 \\
(0.79- \\
-3.69)\end{array}$ \\
\hline $\begin{array}{l}\text { Southern Sub- } \\
\text { Saharan } \\
\text { Africa }\end{array}$ & $\begin{array}{l}3.24 \\
(3.86- \\
2.67)\end{array}$ & $\begin{array}{l}11.26 \\
(13.32- \\
9.4)\end{array}$ & $\begin{array}{l}0.61 \\
(0.7- \\
0.54)\end{array}$ & $\begin{array}{l}3.63 \\
(4.33- \\
3.02)\end{array}$ & $\begin{array}{l}8.12 \\
(9.68- \\
6.78)\end{array}$ & $\begin{array}{l}0.46 \\
(0.58- \\
0.35)\end{array}$ & $\begin{array}{l}-1.01 \\
(-0.88 \\
- \\
-1.15)\end{array}$ & $\begin{array}{l}-1.22 \\
(2.2- \\
-4.53)\end{array}$ \\
\hline
\end{tabular}




\begin{tabular}{|c|c|c|c|c|c|c|c|c|}
\hline Characteristics & 1990 & & & 2019 & & & 1990- & 019 \\
\hline $\begin{array}{l}\text { Western Sub- } \\
\text { Saharan } \\
\text { Africa }\end{array}$ & $\begin{array}{l}20.65 \\
(23.9- \\
17.42)\end{array}$ & $\begin{array}{l}23.09 \\
(26.31- \\
19.73)\end{array}$ & $\begin{array}{l}2.57 \\
(3.18- \\
2.06)\end{array}$ & $\begin{array}{l}37.1 \\
(42.72- \\
31.39)\end{array}$ & $\begin{array}{l}16.16 \\
(18.42- \\
13.9)\end{array}$ & $\begin{array}{l}4.07 \\
(5.33- \\
3.13)\end{array}$ & $\begin{array}{l}-0.97 \\
(-0.87 \\
- \\
-1.06)\end{array}$ & $\begin{array}{l}-1.39 \\
(1.25- \\
-3.97)\end{array}$ \\
\hline $\begin{array}{l}\text { High-middle } \\
\text { SDI }\end{array}$ & $\begin{array}{l}18.37 \\
(22.81- \\
14.64)\end{array}$ & $\begin{array}{l}2.92 \\
(3.63- \\
2.34)\end{array}$ & $\begin{array}{l}2.29 \\
(2.54- \\
2.09)\end{array}$ & $\begin{array}{l}15.41 \\
(18.6- \\
12.45)\end{array}$ & $\begin{array}{l}2.18 \\
(2.63- \\
1.78)\end{array}$ & $\begin{array}{l}0.57 \\
(0.64- \\
0.51)\end{array}$ & $\begin{array}{l}-0.57 \\
(-0.3- \\
-0.83)\end{array}$ & $\begin{array}{l}-5.25 \\
(4.63- \\
-14.2)\end{array}$ \\
\hline High SDI & $\begin{array}{l}11.15 \\
(13.92- \\
8.86)\end{array}$ & $\begin{array}{l}2.62 \\
(3.29- \\
2.09)\end{array}$ & $\begin{array}{l}0.27 \\
(0.3- \\
0.25)\end{array}$ & $\begin{array}{l}10.86 \\
(12.74- \\
9.14)\end{array}$ & $\begin{array}{l}2.38 \\
(2.8- \\
2.01)\end{array}$ & $\begin{array}{l}0.15 \\
(0.17- \\
0.13)\end{array}$ & $\begin{array}{l}-0.45 \\
(-0.19 \\
- \\
-0.71)\end{array}$ & $\begin{array}{l}-1.81 \\
(18.99 \\
- \\
-18.98)\end{array}$ \\
\hline $\begin{array}{l}\text { Low-middle } \\
\text { SDI }\end{array}$ & $\begin{array}{l}45.51 \\
(54.38- \\
38)\end{array}$ & $\begin{array}{l}8.15 \\
(9.69- \\
6.82)\end{array}$ & $\begin{array}{l}17.48 \\
(19.69- \\
15.45)\end{array}$ & $\begin{array}{l}44.46 \\
(52.08- \\
37.58)\end{array}$ & $\begin{array}{l}4.65 \\
(5.43- \\
3.93)\end{array}$ & $\begin{array}{l}9.87 \\
(11.42- \\
8.36)\end{array}$ & $\begin{array}{l}-1.92 \\
(-1.76 \\
- \\
-2.08)\end{array}$ & $\begin{array}{l}-3.69 \\
(-0.74 \\
-6.55)\end{array}$ \\
\hline Low SDI & $\begin{array}{l}43.49 \\
(50.63- \\
36.65)\end{array}$ & $\begin{array}{l}18.04 \\
(20.86- \\
15.26)\end{array}$ & $\begin{array}{l}9.78 \\
(11.19- \\
8.4)\end{array}$ & $\begin{array}{l}70.58 \\
(82.16- \\
60.01)\end{array}$ & $\begin{array}{l}12.65 \\
(14.6- \\
10.77)\end{array}$ & $\begin{array}{l}13.46 \\
(15.8- \\
11.38)\end{array}$ & $\begin{array}{l}-1.17 \\
(-1.07 \\
- \\
-1.28)\end{array}$ & $\begin{array}{l}-1.55 \\
(0.66- \\
-3.71)\end{array}$ \\
\hline Middle SDI & $\begin{array}{l}44.35 \\
(53.47- \\
36.59)\end{array}$ & $\begin{array}{l}4.69 \\
(5.62- \\
3.88)\end{array}$ & $\begin{array}{l}9.94 \\
(10.95- \\
9.07)\end{array}$ & $\begin{array}{l}39.34 \\
(46.14- \\
33.05)\end{array}$ & $\begin{array}{l}3.14 \\
(3.67- \\
2.64)\end{array}$ & $\begin{array}{l}3.75 \\
(4.23- \\
3.28)\end{array}$ & $\begin{array}{l}-1.13 \\
(-0.91 \\
- \\
-1.34)\end{array}$ & $\begin{array}{l}-4.37 \\
(0.93- \\
-9.4)\end{array}$ \\
\hline
\end{tabular}

Regional level

At the regional level, the incidence of HDP in 2019 was highest in South Asia [3.84 million (95\% UI 3.16 to 4.62 million)], western sub-Saharan Africa [3.71 million (95\% UI 3.14 to 4.27 million)] and eastern sub-Saharan Africa [3.12 million (95\% UI 2.64 to 3.63 million)]. Conversely, Australasia [30.11 thousand ( $95 \%$ UI 23.08 to 38.67 thousand)], Oceania [37.06 thousand ( $95 \%$ UI 29.64 to 46.29 thousand)] and Central Europe [78.06 thousand (95\% UI 64.04 to 94.23 thousand)] had the lowest incident estimates (Table 1). Western subSaharan Africa [1615.93 (95\% UI 1390.04 to 1842.10)], central sub-Saharan Africa [1517.60 (95\% UI 1258.91 to 1790.02)] and eastern sub-Saharan Africa [1495.83 (95\% UI 1271.30 to 1722.85)] had the highest HDP ASIRs, while these rates were lowest in East Asia [98.03 (95\% UI 80.58 to 120.27)], high-income Asia Pacific [144.25 (95\% UI 123.89 to 168.69)] and Central Europe [160.98 (95\% UI 132.18 to 192.85)] (Table 1). Central sub-Saharan Africa [2.80 (95\% UI 2.12 to 3.53)], eastern sub-Saharan Africa [2.40 (95\% UI 1.92 to 2.93)] and western sub-Saharan Africa [1.77 (95\% UI 1.36 to 2.31)] had the highest ASDRs in 2019, while high-income Asia Pacific [0.01 (95\% UI 0.01 to 0.01)], Western Europe (0.01 (95\% UI 0.01 to 0.01)) and Australasia (0.01 ( $95 \%$ UI 0.01 to 0.02)) had the lowest ASDRs (Supplementary Table 1). The EAPCs in the ASIR and ASDR from 1990 to 2019 varied across regions. While all regions showed a decreasing incidence trend, Eastern Europe, Western Europe and Andean Latin America had potential increasing trends (Table 1). The majority of regions showed decreasing EAPCs in the ASDR trends, except high-income North America and the Caribbean, which 
displayed potential increasing trends (Table 1). The age-standardized DALYs, YLLs and YLDs in 2019 are shown in online supplementary table 2, with decreasing trends from 1990 to 2019 (Supplementary Fig. 1).

National level

ASIRs per 100,000 population estimates of HDP in 2019 ranged from 36.34 to 2278.25 . Chad [2278.25 ( $95 \%$ UI 1191.82 to 2675.20)], Niger [2256.95 (95\% UI 1883.97 to 2644.81)] and Somalia [2251.26 (95\% UI 1893.54 to 2597.09)] were the countries with the highest ASIRs estimates in 2019. Korea [36.34 (95\% UI 29.61 to 45.73)], Canada [49.13 (95\% UI 41.84 to 57.00)] and Luxembourg [58.27 (95\% UI 45.34 to 74.77 )] had the lowest estimates (Fig. 1a and online Supplementary Table 3). All age prevalence number estimates in 2019 differed greatly among countries, with the lowest in Niue Island [0.60 (95\% UI 0.36 to 0.89$)$ ], Tokelau [0.81 ( $95 \%$ UI 0.48 to 1.21)], Tuvalu [4.14 (95\% UI 2.50 to 6.24)] and the highest in India [423997.43 (95\% UI 266164.82 to 623364.13 )], Nigeria [367632.29 (95\% UI 234623.34 to 518038.38 )], Pakistan [1 43309.61 (95\% UI 89458.08 to 209804.74)] (data shown in Fig. 1b and online

Supplementary Table 4)

The EAPC in ASIR estimates from 1990 to 2019 differed substantially among countries. A total of 174 countries and regions displayed decreasing trends, while 30 countries and regions had increasing trends. Nepal [-4.64 (95\% Cl-4.83 to -4.45)], Qatar [-3.97 (95\% Cl-4.19 to -3.75)] and Oman [-3.68 (95\% Cl -3.86 to $-3.50)$ ] showed the greatest decreasing trends. Ecuador [2.09 (95\% Cl 1.90 to 2.28)], Switzerland [1.55 (95\% Cl 1.14 to 1.96$)$ ] and Denmark [1.52 (95\% $\mathrm{Cl} 0.98$ to 2.06$)$ ] showed the greatest increasing trends (Fig. $1 \mathrm{c}$ and online Supplementary Table 5).

Age distribution of HDP

From 1990 to 2019, global HDP incidence, prevalence, death and YLDs were highest in populations aged 2529 years, followed by populations aged 30-34 and 20-24 years (Fig. 2). The incidence trend of HDP was similar to the normal distribution, with the lowest in those 10-14 and 55-59 years old. The same trends were also observed the prevalence, death and YLD data. When the number of pregnant women was estimated according to the fertility rate, the incidence rate of HDP based on pregnant women was calculated, and it was found that the incidence rate was the lowest in group aged 25-29 years but higher in the youngest and oldest age groups (Fig. 2). The same trends were also observed in prevalence, death and YLD data.

Burden of HDP by SDI and HDI

Generally, a positive association between the ASIR and SDI was found for all countries and regions in 2019. The ASIRs were higher in countries/regions with lower SDIs (Fig. 3a and online Supplementary Table 6). The SDIs for Chad, Niger, and Somalia, the three countries with the highest incidence rates, were $0.24,0.16$, and 0.08 , respectively. The SDIs for Korea, Canada, and Luxembourg, the three countries with the lowest incidence rates, were $0.88,0.87$, and 0.90 , respectively. The incident HDP case number increased globally, which was mainly attributed to the increasing trend of low SDI areas (Supplementary Fig. 2).

Similarly, a positive association between the ASIR and HDI was also found for all countries and regions in 2019. The ASIRs were higher in countries/regions with lower HDIs (Fig. 3b and online Supplementary table 7). 
The HDIs of Chad, Niger, and Burundi, the three countries with the highest incidence rates, were 0.401, 0.377, and 0.423 , respectively. The SDIs of Korea, Canada, and Luxembourg, the three countries with the lowest incidence rates, were $0.906,0.922$, and 0.909 , respectively.

Risk factors for HDP burden

The global HDP ASDR attributable to all risk factors decreased from 0.34 (95\% UI 0.12 to 0.54 ) to 0.15 (95\% UI 0.05 to 0.25$)$ per 100,000 population between 1990 and 2019 . All risk factors were mainly attributed to iron deficiency.

\section{Discussion}

HDP is characterized by high blood pressure and a significantly high protein level in urine. It is one of the major causes of maternal mortality worldwide.(16) For the first time, we analyzed the incidence trends of HDP at the global, regional and national levels. From 1990 to 2019, the ASIR of HDP decreased by an annual average of $0.68 \%$, while the total number of incident cases increased by $10.92 \%$. This pattern appears to suggest a major public health problem, as the ASIR has not substantially improved. The number of incident cases increased, probably due to population growth and multiple gestations. Both the number of deaths due to and ASDR of HDP showed decreasing trends, which may be due to the advancement of medical skills and gradually increasing attention to HDP by clinicians.(8)

To the best of our knowledge, this is the first study to examine the associations of the ASR of and EAPC in HDP with SDI and HDI by country. Our study found that although the number of incident cases of HDP increased from 1990 to 2019, the incidence rate showed a decreasing trend, which is related to the increase in the global population. Moreover, the number of pregnant women who died due to HDP also showed a decreasing trend, indicating that the management of pregnant women and medical interventions are constantly improving globally. Obstetricians have known for many years women with HDP generally have low total family incomes because the mortality rate of HDP is inversely correlated with average family income and maternal deaths from HDP/eclampsia are highest in areas of poverty.(17) A previous study showed that the incidence of HDP varied according to family income. When grouped by income, the highest incidence rates of preeclampsia were observed in upper middle-income countries, whereas eclampsia appeared to be more frequent in lower middle-income countries.(7) In our study, both the incident case numbers and rates were highest in the low-SDI areas. At the national level, incidence also showed a decreasing trend as SDI increased. This trend was also observed between ASIR and HDI.

It is well known that the risk of preeclampsia is higher in older pregnant women than in younger pregnant women.(17) Previous studies reported that the risk of preeclampsia increased in an approximately linear manner with maternal age and that this pattern was similar in nulliparae and multiparae.(18) Another study identified the incidence rates of pregnancy complications in nulliparous and multiparous Chinese women with advanced maternal age using a community-based prospective cohort. The findings suggested that women with advanced maternal age should be regarded as high-risk for pregnancy complications, including HDP.(19) A large cohort of Japanese women with singleton pregnancies also indicated that advanced maternal age was a risk factor for HDP.(11) According to GBD database information, our study found that the incidence rate 
of HDP was highest in the group aged 25-29 years because the population included in the calculation comprised all women in that age group, not only pregnant women. This phenomenon also occurred in the "Maternal Health Report" (https://maternalhealthatlas.org/).(20) By using fertility rate and other information to estimate the number of pregnant women during a period of time and then calculating the incidence of HDP, the results showed that the incidence in the group aged 25-29 years was the lowest, which is similar to the results of previous studies. HDP is more likely to occur at the extremes of reproductive age. It is believed that women with advanced maternal age have an increased rate of HDP because of risk factors such as obesity and diabetes.(21) Women with advanced age are more likely to develop atherosclerosis, which affects the small arteries, leading to hypertension, than younger women. $(17,22)$ Teenage pregnancy is largely associated with adverse pregnancy outcomes such as preterm delivery, preeclampsia and low birth weight.(23) These outcomes might be related to poverty, inadequate nutrition, impaired health before pregnancy, marital status, or low education level.(24) However, some studies have also found that there is a linear relationship between the occurrence of HDP and age in women 16-44 years old.(25)

Women's blood lipids change significantly in early pregnancy. As gestational age increases, blood lipid levels will rise to varying degrees. In recent years, researchers have paid increasing attention to the relationship between abnormal lipid metabolism and HDP. Researchers have found that approximately $20-40 \%$ of preeclampsia patients have subcutaneous fat foam cell deposits and intraarterial cellulose and platelet aggregation.(26) The results of animal model studies speculate that vascular intima injury and subintimal fat deposition will lead to acute atherosclerosis of the uterine artery.(27) Population study data show that fasting triglycerides, total cholesterol and low-density lipoprotein-c in the HDP group were significantly higher than those in the healthy control group, and early detection of these parameters may help to better manage HDP. (28) On the other hand, ambient air pollution is a complex mixture composed of gases, aerosols, particulate matter, etc. The main components include nitrogen oxides, sulfur oxides, and particulate matter $\left(\mathrm{PM}_{10}\right.$ and $\mathrm{PM}_{2.5}$ ). Air pollution poses a serious risk to the health of the population. The GBD results show that in 2019, only atmospheric $\mathrm{PM}_{2.5}$ pollution directly or indirectly caused 6.67 million deaths and 213.28 million DALYs. At present, some studies have discussed the possible association between air pollution and HDP. $(29,30)$ However, at present, the focus of academic debate is mainly focused on which types of air pollutants affect HDP and whether there is a sensitive period of exposure.(31) One study based on a large, contemporary nationwide cohort suggests that early pregnancy is a critical exposure window, particularly for transport emission-related pollutants ( $\mathrm{NO}, \mathrm{PM}_{2.5}$, and $\mathrm{PM}_{10}$ ), in relation to the risk of HDP. In addition, $\mathrm{SO}_{2}$ exposure both before conception and during early gestation illustrated a consistent pattern of $18-22 \%$ higher risk of HDP.(32) A study recruited 22041 pregnant women and found that high exposure to air pollution in the early stage of pregnancy and high exposure to air pollution throughout pregnancy were associated with HDP (particulate matter $\left(\mathrm{PM}_{2.5}\right)$ : odds ratio $(\mathrm{OR})=1.33,95 \% \mathrm{Cl}: 1.18-1.49, \mathrm{NO}_{2}$ : $\mathrm{OR}=1.21,95 \% \mathrm{Cl}: 1.09-1.35, \mathrm{SO}_{2}$ : $\mathrm{OR}=1.13,95 \% \mathrm{Cl}: 1.01-1.25, \mathrm{CO}: \mathrm{OR}=1.12,95 \% \mathrm{Cl}: 1.03-1.22)$.(33) Studies by Mobasher and others suggested that only $\mathrm{PM}_{2.5}$ exposure in early pregnancy $(\mathrm{OR}=9.10,95 \% \mathrm{Cl}: 3.33-24.6)$ and $\mathrm{CO}$ exposure in the early and middle stages of pregnancy (early pregnancy: $\mathrm{OR}=4.96,95 \% \mathrm{Cl}: 1.85-13.31$, second trimester: $\mathrm{OR}=$ 2.05, 95\% Cl: 1.22-3.46) increase the risk of HDP.(34) However, some studies found that in unadjusted analyses, $\mathrm{PM}_{2.5}$ and $\mathrm{NO}_{2}$ were positively correlated with $\mathrm{HDP}$, but after adjusting for covariates, there were no significant correlations between $\mathrm{PM}_{2.5}$ and $\mathrm{NO}_{2}$ exposure in the first and second trimesters of pregnancy and 
HDP.(35) However, although there are indicators related to lipid metabolism and air pollution in the GBD database, there was a lack of relevant data. We could analyze only behavior-related risk factors.

Our study found a decreasing trend of HDP due to iron deficiency from 1990 to 2019, which may be related to an increasing number of obstetricians prescribing iron supplements during pregnancy. However, there is still some controversy about the relationship between iron supplementation during pregnancy and the occurrence of HDP. Maintaining optimal iron levels is a delicate balance, with high levels associated with toxicity. One study found that pregnant women who subsequently developed HDP had lower serum iron levels in the first trimester than those who did not. However, other studies showed different trends.(36) A different study indicated that serum iron levels measured at 20 weeks gestation were higher in women with preeclampsia but no gestational hypertension than in women with normotensive pregnancies.(37) Differences in these findings can potentially be explained by different methodologies and gestational times of serum sample collection.(36) This may indicate that adequate iron intake is a concern in pregnancy.(38)

\section{Conclusions}

Our study provides a comprehensive overview of the global HDP burden. Although there were variations between regions and countries in the prevalence of, incidence of and mortality due to HDP, its burden is decreasing in most countries and in all regions. This is mainly because more attention has been paid to prenatal examinations and health education. The prevalence of HDP was associated with SDI and HDI. Further investigations should focus on forecasting the global disease burden of specific classifications of HDP and modifiable risk factors.

\section{Abbreviations}

ACOG

American Congress of Obstetricians and Gynecologists

ASR

age-standardized rate

ASDR

age-standardized deaths rate

ASIR

age-standardized incidence rate

$\mathrm{Cl}$

confidence intervals

DALY

disability-adjusted life year

EAPC

estimated annual percentage change

GBD

Global Burden of Diseases, Injuries, and Risk Factors Study

GHDx

Global Health Data Exchange

Page 11/19 
GLM

generalized linear model

HDP

hypertensive disorders of pregnancy

HDI

human development index

HELLP

hemolytic anemia, elevated liver function and low platelet count syndrome

ISH

International Society of Hypertension

ISSHP

International Society for the Study of Hypertension in Pregnancy

OR

odds ratio

PM

particulate matter

SDI

sociodemographic index

UI

uncertainty intervals

YLD

years lived with disability

YLL

years of life lost

\section{Declarations}

Ethics approval and consent to participate

Not applicable

Consent for publication

Not applicable

\section{Availability of data and materials}

The datasets supporting the conclusions of this article are included within the article (and its additional files) and can be found in the GHDx database.

\section{Competing interests}

The authors declare that they have no competing interests.

\section{Funding}


This study was not funded by any institution or individual.

\section{Authors' contributions}

All authors read, critically reviewed and approved the final manuscript. $\mathrm{HZ}$ and $\mathrm{WW}$ designed the research; $X X$, TY, WW and YYW collected and arranged the data. WW, FZ and ZJZ verified the accuracy of the data; WW, XX, FZ and ZJZ performed the statistical analysis and made the figures and tables; WW and HZ wrote and revised the manuscript.

\section{Acknowledgments}

We thank the Global Burden of Disease Study and World Health Organization for their work.

\section{References}

1. Hypertension in pregnancy. Report of the American College of Obstetricians and Gynecologists' Task Force on Hypertension in Pregnancy. Obstetrics gynecology. 2013;122(5):1122-31.

2. Brown M, Magee L, Kenny L, Karumanchi S, McCarthy F, Saito S, et al. Hypertensive Disorders of Pregnancy: ISSHP Classification, Diagnosis, and Management Recommendations for International Practice. Hypertension (Dallas, Tex: 1979). 2018;72(1):24-43.

3. Unger T, Borghi C, Charchar F, Khan N, Poulter N, Prabhakaran D, et al. 2020 International Society of Hypertension Global Hypertension Practice Guidelines. Hypertension (Dallas, Tex: 1979). 2020;75(6):1334-57.

4. Garovic V, White W, Vaughan L, Saiki M, Parashuram S, Garcia-Valencia O, et al. Incidence and Long-Term Outcomes of Hypertensive Disorders of Pregnancy. J Am Coll Cardiol. 2020;75(18):2323-34.

5. Ananth C, Keyes K, Wapner R. Pre-eclampsia rates in the United States, 1980-2010: age-period-cohort analysis. BMJ. 2013;347:f6564.

6. Levine R, Hauth J, Curet L, Sibai B, Catalano P, Morris C, et al. Trial of calcium to prevent preeclampsia. N Engl J Med. 1997;337(2):69-76.

7. Abalos E, Cuesta C, Grosso A, Chou D, Say L. Global and regional estimates of preeclampsia and eclampsia: a systematic review. Eur J Obstet Gynecol Reprod Biol. 2013;170(1):1-7.

8. Auger N, Luo Z, Nuyt A, Kaufman J, Naimi A, Platt R, et al. Secular Trends in Preeclampsia Incidence and Outcomes in a Large Canada Database: A Longitudinal Study Over 24 Years. Can J Cardiol. 2016;32(8):987.e15-23.

9. Rezende K, Bornia R, Esteves A, Cunha A, Amim Junior J. Preeclampsia. Prevalence and perinatal repercussions in a University Hospital in Rio de Janeiro, Brazil. Pregnancy hypertension. 2016;6(4):253-5.

10. Li X, Tan H, Huang X, Zhou S, Hu S, Wang X, et al. Similarities and differences between the risk factors for gestational hypertension and preeclampsia: A population based cohort study in south China. Pregnancy hypertension. 2016;6(1):66-71.

11. Shiozaki A, Matsuda Y, Satoh S, Saito S. Comparison of risk factors for gestational hypertension and preeclampsia in Japanese singleton pregnancies. J Obstet Gynaecol Res. 2013;39(2):492-9. 
12. Yamada T, Obata-Yasuoka M, Hamada H, Baba Y, Ohkuchi A, Yasuda S, et al. Isolated gestational proteinuria preceding the diagnosis of preeclampsia - an observational study. Acta obstetricia et gynecologica Scandinavica. 2016;95(9):1048-54.

13. Global regional. and national age-sex-specific mortality for 282 causes of death in 195 countries and territories, 1980-2017: a systematic analysis for the Global Burden of Disease Study 2017. Lancet (London, England). 2018;392(10159):1736-88.

14. Organization WH, Fund UNP. Reproductive Health in Refugee Situations. An Inter-Agency Field Manual. Geneva Switzerland Unhcr. 1995.

15. Global regional. and national age-sex specific all-cause and cause-specific mortality for 240 causes of death, 1990-2013: a systematic analysis for the Global Burden of Disease Study 2013. Lancet (London, England). 2015;385(9963):117-71.

16. Osungbade $\mathrm{K}$, Ige $\mathrm{O}$. Public health perspectives of preeclampsia in developing countries: implication for health system strengthening. Journal of pregnancy. 2011;2011:481095.

17. Saito S Preeclampsia: Basic, Genomic, and Clinical: Springer; 2018.

18. Funai E, Paltiel O, Malaspina D, Friedlander Y, Deutsch L, Harlap S. Risk factors for pre-eclampsia in nulliparous and parous women: the Jerusalem perinatal study. Paediatr Perinat Epidemiol. 2005;19(1):59-68.

19. Luo J, Fan C, Luo M, Fang J, Zhou S, Zhang F. Pregnancy complications among nulliparous and multiparous women with advanced maternal age: a community-based prospective cohort study in China. BMC Pregnancy Childbirth. 2020;20(1):581.

20. Evaluation IfHMa. Making the World a Healthier Place for Mothers: Trends and Opportunities for Action in Maternal Health. 2019. Contract No.: Seattle.

21. Robles RG, Ayala P, Olaya-C M, Martinez R, Gil F. Risk factors and fetal outcomes for preeclampsia in a Colombian cohort. Heliyon. 2020.

22. Cox L, Redman C. The role of cellular senescence in ageing of the placenta. Placenta. 2017;52:139-45.

23. Ganchimeg T, Mori R, Ota E, Koyanagi A, Gilmour S, Shibuya K, et al. Maternal and perinatal outcomes among nulliparous adolescents in low- and middle-income countries: a multi-country study. BJOG: an international journal of obstetrics gynaecology. 2013;120(13):1622-30. discussion 30.

24. Patil A, Patel N. Impact of Adolescent Pregnancy on Obstetric Outcome. Indian Journal of Trauma Emergency Pediatrics. 2017;9(2):117.

25. Li S, Li H, Li C, He X, Wang Y. Development and Validation of a Nomogram for Predicting the Risk of Pregnancy-Induced Hypertension: A Retrospective Cohort Study. Journal of women's health (2002). 2020.

26. Staff A, Dechend R, Pijnenborg R. Learning from the placenta: acute atherosis and vascular remodeling in preeclampsia-novel aspects for atherosclerosis and future cardiovascular health. Hypertension (Dallas, Tex: 1979). 2010;56(6):1026-34.

27. Chatzizisis Y, Coskun A, Jonas M, Edelman E, Feldman C, Stone P. Role of endothelial shear stress in the natural history of coronary atherosclerosis and vascular remodeling: molecular, cellular, and vascular behavior. J Am Coll Cardiol. 2007;49(25):2379-93. 
28. Sahu S, Abraham R, Vedavalli R, Daniel M. Study of lipid profile, lipid peroxidation and vitamin E in pregnancy induced hypertension. Indian J Physiol Pharmacol. 2009;53(4):365-9.

29. Dadvand P, Figueras F, Basagaña X, Beelen R, Martinez D, Cirach M, et al. Ambient air pollution and preeclampsia: a spatiotemporal analysis. Environmental health perspectives. 2013;121:1365-71.

30. Malmqvist E, Jakobsson K, Tinnerberg H, Rignell-Hydbom A, Rylander L. Gestational diabetes and preeclampsia in association with air pollution at levels below current air quality guidelines. Environmental health perspectives. 2013;121(4):488-93.

31. Pedersen M, Stayner L, Slama R, Sørensen M, Figueras F, Nieuwenhuijsen M, et al. Ambient air pollution and pregnancy-induced hypertensive disorders: a systematic review and meta-analysis. Hypertension (Dallas, Tex: 1979). 2014;64(3):494-500.

32. Zhu Y, Zhang C, Liu D, Ha S, Kim S, Pollack A, et al. Ambient Air Pollution and Risk of Gestational Hypertension. Am J Epidemiol. 2017;186(3):334-43.

33. Hu H, Ha S, Roth J, Kearney G, Talbott E, Xu X. Ambient Air Pollution and Hypertensive Disorders of Pregnancy: A Systematic Review and Meta-analysis. Atmospheric environment (Oxford, England: 1994). 2014;97:336 - 45.

34. Mobasher Z, Salam M, Goodwin T, Lurmann F, Ingles S, Wilson M. Associations between ambient air pollution and Hypertensive Disorders of Pregnancy. Environmental research. 2013;123:9-16.

35. Savitz D, Elston B, Bobb J, Clougherty J, Dominici F, Ito K, et al. Ambient Fine Particulate Matter, Nitrogen Dioxide, and Hypertensive Disorders of Pregnancy in New York City. Epidemiology (Cambridge, Mass). 2015;26(5):748 - 57.

36. Tande D, Ralph J, Johnson L, Scheett A, Hoverson B, Anderson C. First trimester dietary intake, biochemical measures, and subsequent gestational hypertension among nulliparous women. J Midwifery Women Health. 2013;58(4):423-30.

37. Fenzl V, Flegar-Meštrić Z, Perkov S, Andrišić L, Tatzber F, Žarković N, et al. Trace elements and oxidative stress in hypertensive disorders of pregnancy. Archives of gynecology obstetrics. 2013;287(1):19-24.

38. Georgieff M. Iron deficiency in pregnancy. American journal of obstetrics gynecology. 2020;223(4):51624.

\section{Figures}



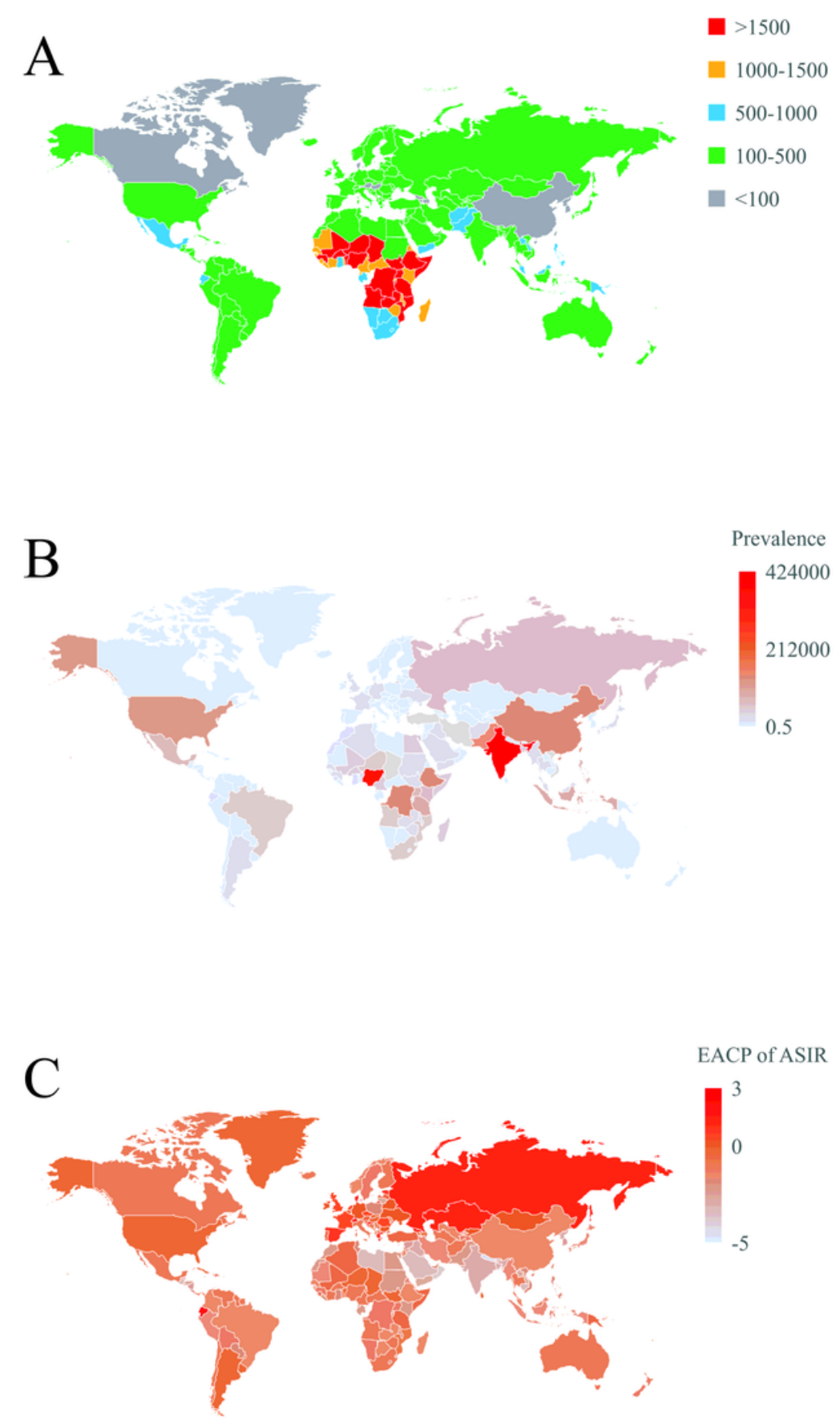

\section{Figure 1}

Overview of HDP by country and region for both sexes combined. (A) The prevalence of HDP in 2019. (B) The ASIR of HDP per 100,000 population in 2019. (C) The EAPC in the ASDR of HDP from 1990 to 2019. ASIR, agestandardized incidence rate; ASDR, age-standardized death rate; EAPC, estimated annual percentage change; HDP, hypertensive disorders of pregnancy. Note: The designations employed and the presentation of the material on this map do not imply the expression of any opinion whatsoever on the part of Research Square concerning the legal status of any country, territory, city or area or of its authorities, or concerning the delimitation of its frontiers or boundaries. This map has been provided by the authors. 
A

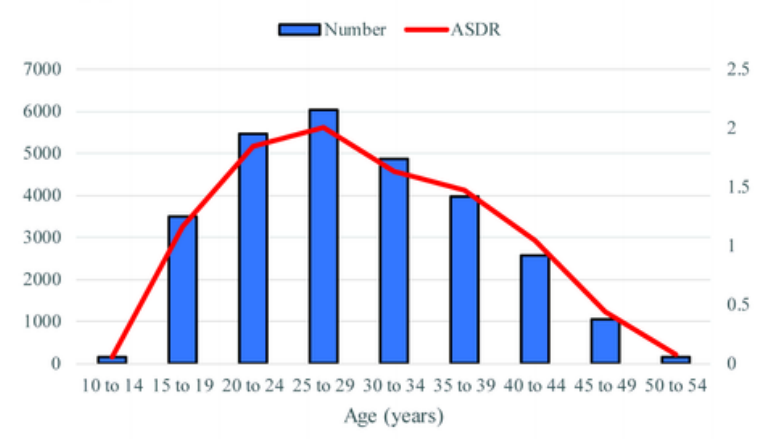

$\mathrm{C}$

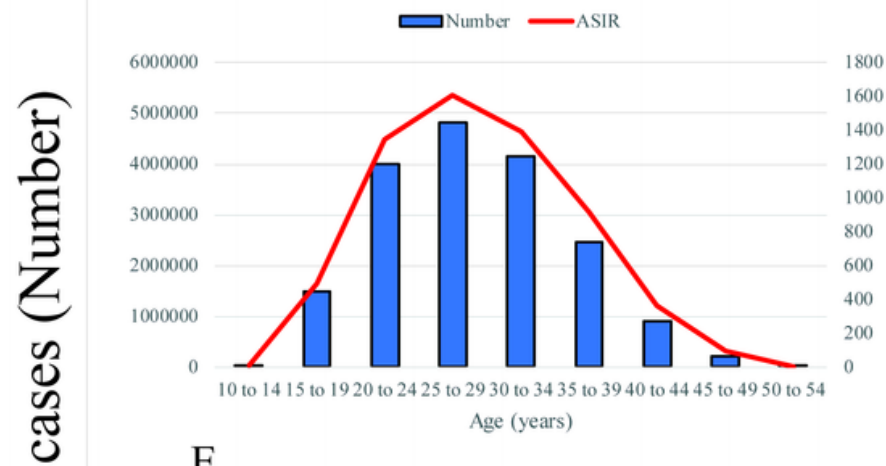

$\mathrm{E}$

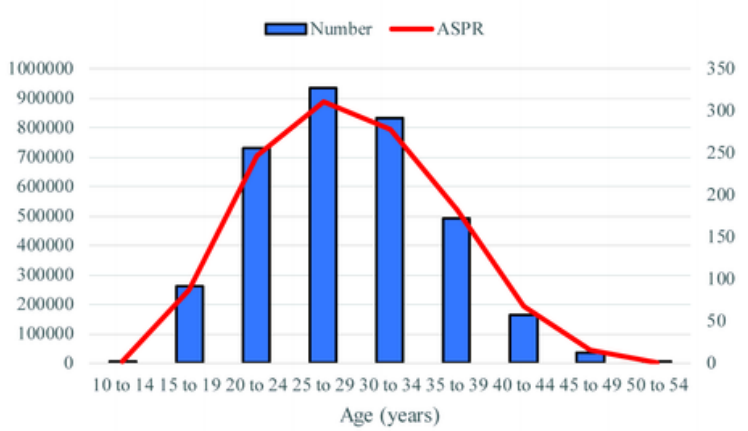

G

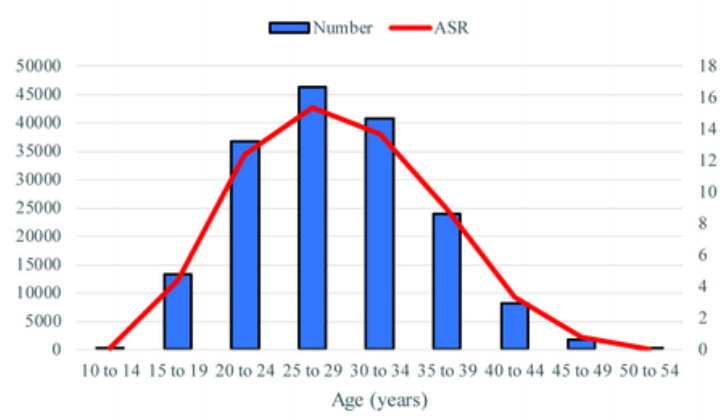

B

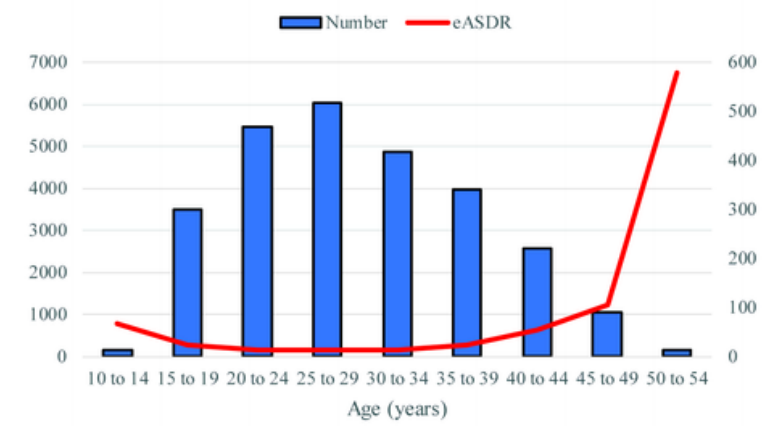

$\mathrm{D}$
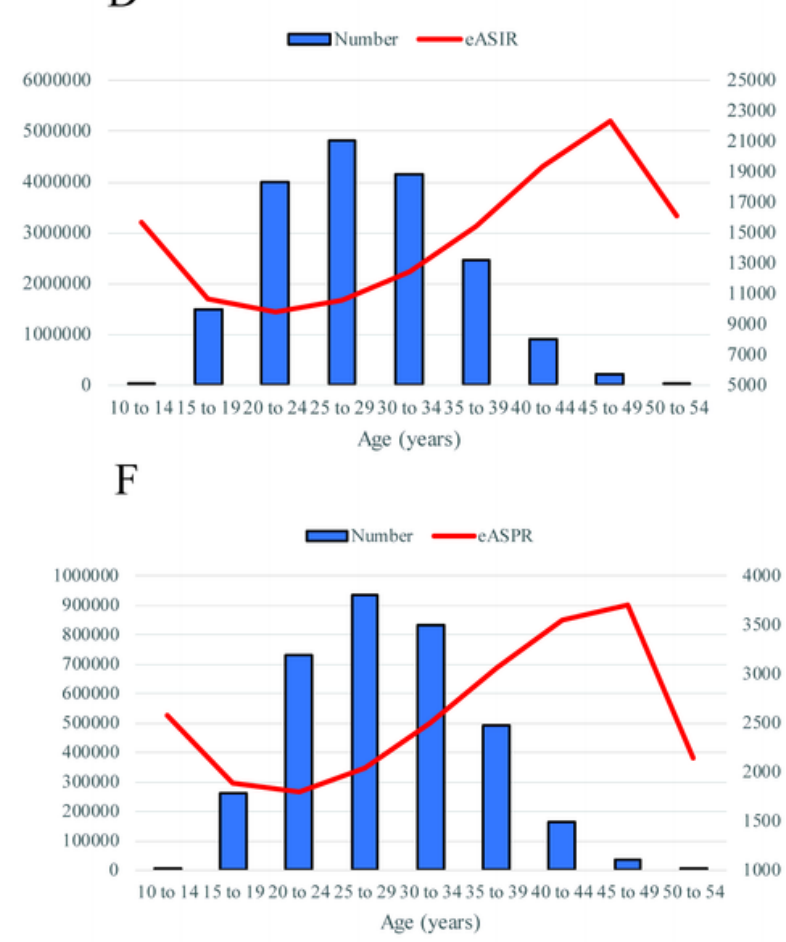

$\mathrm{H}$

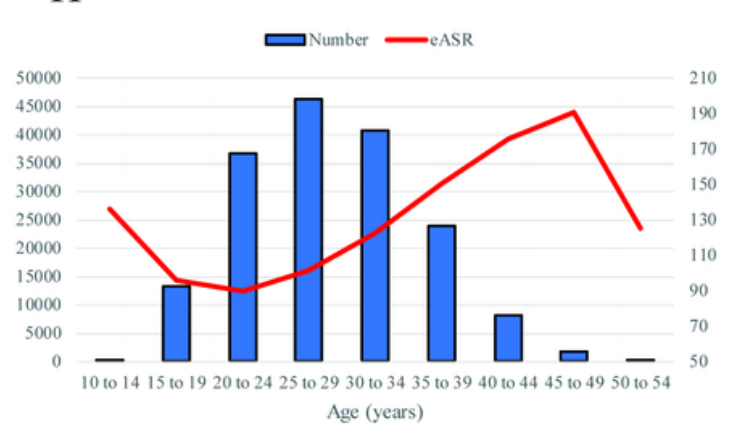

Figure 2

Global number of cases and ASRs per 100,000 population by age in 2017. (A) The global number of deaths and ASDRs. (B) The global number of deaths and eASDR. (C) The global number of incident cases and ASIR. (D) The global number of incident cases and eASIR. (E) The global number of prevalence cases and ASPR. (F) The global number of prevalent cases and eASPR. (G) The global number of YLDs and ASR of YLDs. (H) The global number of YLDs and eASR of YLDs. ASIR, age-standardized incidence rate; eASIR, estimated agestandardized incidence rate according to the number of pregnant women; ASDR, age-standardized death rate; eASDR, estimated age-standardized death rate according to the number of pregnant women; ASPR, age- 
standardized prevalence rate; eASPR, estimated age-standardized prevalence rate according to the number of pregnant women; ASR, age-standardized rate; eASR, estimated age-standardized rate according to the number of pregnant women; YLD, years lived with disability.
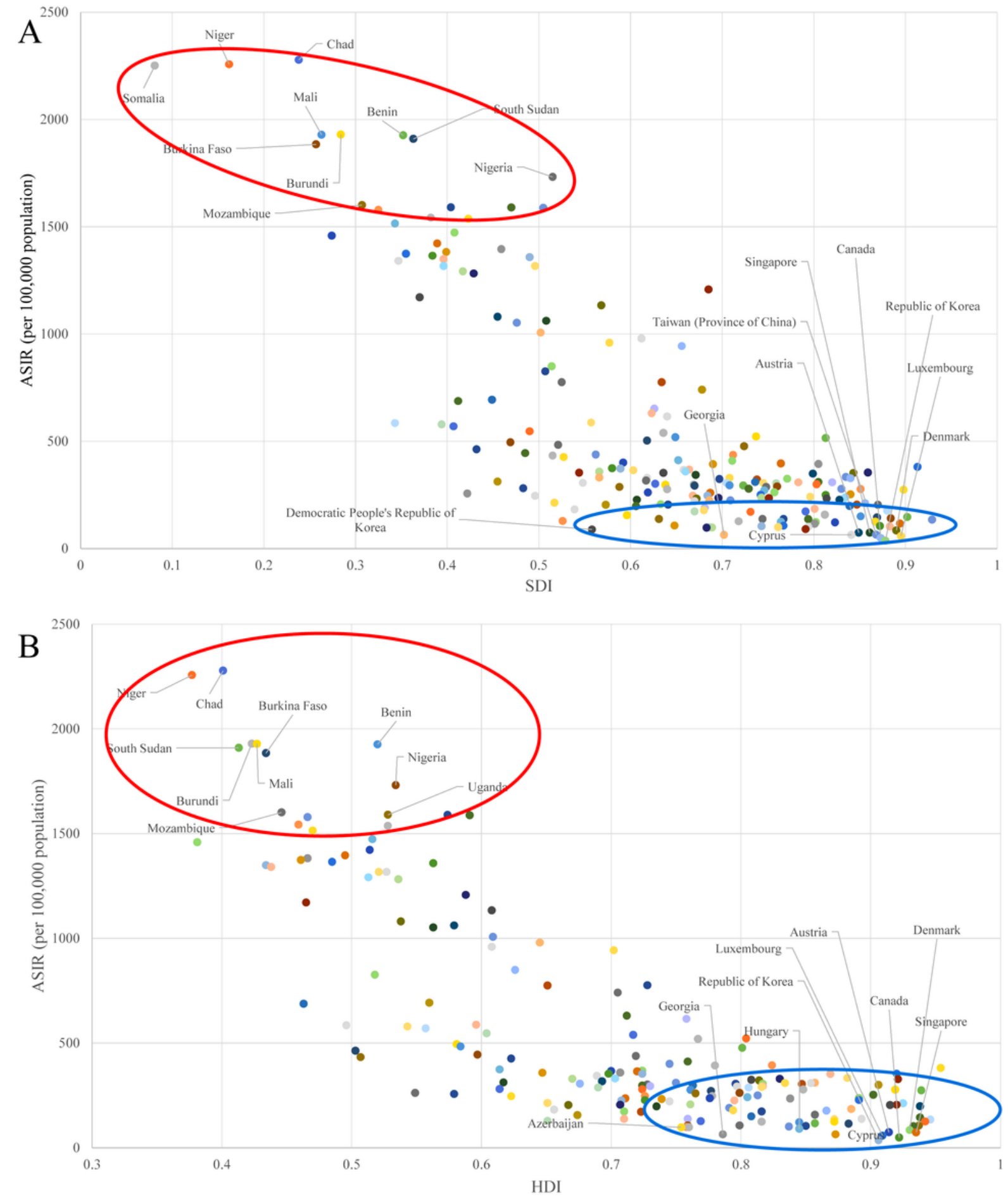

\section{Figure 3}

ASIRs of HDP by country and region and (A) SDIs (with 204 countries and regions) and (B) HDIs (with 187 countries and regions) in 2019. Each point shows the observed ASIR for a specified country or region in 2019. The red circle includes the 10 countries or regions with the highest ASIRs. The blue circle includes the 10 
countries or regions with the lowest ASIRs. ASIR, age-standardized incidence rate; HDP, hypertensive disorders of pregnancy; HDI, human development index; SDI, sociodemographic index.

\section{Supplementary Files}

This is a list of supplementary files associated with this preprint. Click to download.

- sFigure1.tif

- sFigure2.tif

- sTable1.docx

- sTable2.docx

- sTable3.docx

- sTable4.docx

- sTable5.docx

- sTable6.docx

- sTable7.docx 